\title{
Optimization of the cooling system design for a compact high-power LED luminaire
}

\author{
D.V. Pekur ${ }^{1}$, Yu.E. Nikolaenko ${ }^{2}$, V.M. Sorokin ${ }^{1}$ \\ ${ }^{1}$ V. Lashkaryov Institute of Semiconductor Physics, National Academy of Sciences of Ukraine, \\ 41, prosp. Nauky, 03680 Kyiv, Ukraine, \\ E-mail:demid.pekur@gmail.com,vsorokin@isp.kiev.ua \\ ${ }^{2}$ National Technical University of Ukraine "Igor Sikorsky Kyiv Polytechnic Institute”, \\ 37, prosp. Peremohy, 03056 Kyiv, Ukraine, \\ E-mail: y.nikolaenko@kpi.ua
}

\begin{abstract}
Using the method of computer modelling, considered in this paper is optimization of a passive air system design for cooling the powerful LED luminaire based on heat pipes and cooling rings. Thermal and mass characteristics of the cooling system have been studied for various design parameters: distance between rings, thickness of ring materials and thermal loads. It has been shown that, to provide a minimal case temperature of LED source, the optimal distance between cooling rings should be $6 \mathrm{~mm}$, but in this case the mass of cooling system is not least. To reduce the luminaire mass, it is reasonable to choose the distance between the cooling rings equal to $8 \mathrm{~mm}$. Then the temperature of light source increases by only $1.8{ }^{\circ} \mathrm{C}$, or by $2.2 \%$, while the mass of cooling system reduces by $1357 \mathrm{~g}$, or by $20.5 \%$. At the same time, lowering the ring thickness from 2 down to $0.8 \mathrm{~mm}$ can in addition reduce this mass by $2700 \mathrm{~g}$, or by $48.6 \%$. However, when doing so the temperature of LED source case is increased by $5.9^{\circ} \mathrm{C}$. The offered cooling system based on heat pipes is capable to provide the thermal resistance $0.131{ }^{\circ} \mathrm{C} / \mathrm{W}$ when scattering the thermal power $500 \mathrm{~W}$ under the maximum temperature of LED source crystal $135.5{ }^{\circ} \mathrm{C}$. Recommendations for application of the developed cooling system have been formulated.
\end{abstract}

Keywords: LED, cooling system, air cooling, heat pipe, optimization.

https://doi.org/10.15407/spqeo23.01.91

PACS 42.72.-g, 52.80.Mg, 85.60.Jb, 92.60.

Manuscript received 16.01.20; revised version received 20.02.20; accepted for publication 18.03.20; published online 23.03.20.

\section{Introduction}

Currently, LED sources are widely spread in lighting systems for domestic and industrial consumers [1]. One of the arguments for using the LED sources is the durable life span of these sources that can reach 100,000 hours. As usual, this term means the time of facility operation up to failure. Another parameter that is often used is the time of effective operation when device photometric performances are unchanged, i.e., the device characteristics are kept higher or equal to some definite level. Lowering the light flux below this level is considered by LED producers as a life span. To determine this parameter, the producers perform testing LEDs at various temperatures. As it is indicated by testing results, the times of keeping LED characteristics within the limits guaranteed by producer depend on the LED temperature [2].

Besides, the LED temperature influences on the light efficiency of LEDs as well as stability of their color characteristics. Therefore, it is very important to provide the operation regime for LEDs under the temperatures as low as possible [3-5] for all the time of their usage.

New generations of LEDs are characterized by essential growing their power. At the same time, sizes of separate LEDs decrease or remain at the previous formfactor.

It results in increasing the density of heat flux through the case of LEDs, and therefore requirements to their cooling systems constantly grow.

For instance, the LED matrix CITIZEN CLU058 based on COB technology contains 648 crystals produced by Nichia company on the board of the sizes $38 \times 38 \times 1.4 \mathrm{~mm}$ and possesses the power $526 \mathrm{~W}[6,7]$.

To provide operation temperatures for powerful LED lighting devices, they more often use the doublephase heat-transmitting facilities - heat pipes [8-32]. Usage of them allows lowering the thermal resistance of cooling system and, as a consequence, lowering the 
temperature of LEDs, raising their life span and stabilizing the electro-optical parameters. The equivalent heat conductivity can reach more than $10000 \mathrm{~W} /\left(\mathrm{m} \cdot{ }^{\circ} \mathrm{C}\right)$ $[15,33]$, which is considerably higher than that of homogeneous metal materials used for creation of cooling systems (aluminum $-240 \mathrm{~W} /\left(\mathrm{m} \cdot{ }^{\circ} \mathrm{C}\right)$, copper $\left.400 \mathrm{~W} /\left(\mathrm{m} \cdot{ }^{\circ} \mathrm{C}\right)\right)$. These performances of the heat pipes enable to considerably lower the mass of material necessary to construct these cooling systems.

As to their shape, the heat pipes can be of cylindrical [11, 12, 15], L-like [16], U-like [15], T-like [15], flat [28], as well as of other shapes. In some applications, for example, for internal lighting of premises with low ceilings as well as for that in cabins of automobile, marine and city transport, in carriages, etc., it is desirable to mount compact LED luminaires with minimal dimensions along their height. In these LED luminaires, the most suitable are the cooling systems with heat pipes of cylindrical or plane shapes with horizontal or close to it orientation in space.

Development of compact LED luminaires foresees optimization of complex parameters for the cooling systems (configuration of arrangement and parameters of its elements, materials and facilities for heat removal). The currently known methods to calculate the thermal parameters of cooling systems, when they use some simplified analytic expressions, do not enable to optimize parameters of complex and multi-component systems of air cooling. Physical modelling [35] can be considered as the more universal method for such optimization, but it is characterized by considerable laboriousness and financial expenses.

The modern method for optimization and designing the cooling systems is based on application of special programs for computer modelling and analysis [36-38]. These approaches enable to perform both designing the cooling systems and their thermal analysis for a relatively short time.

The aim of this work was to investigate, using the computer modelling, heat performances of the passive air cooling system for a compact powerful LED luminaire, which is based on heat pipes of the cylindrical shape, as well as optimize the construction parameters of this cooling system.

To reach this aim, it was necessary to solve the following tasks:

- to offer a basic version of construction corresponding to the LED luminaire with heat pipes;

- to create computer models of a typical number of cooling systems with various construction parameters;

- to carry out the computer modelling for determining their thermal and mass characteristics;

- to analyze the obtained characteristics;

- to choose the optimal construction parameters of the cooling system, which could provide the least temperature of LED source under the set value of its power;

- to formulate recommendations for practical application of the obtained results when designing the compact powerful LED luminaires.

\section{Construction of the basic version of a compact LED luminaire}

Being aimed at performing investigation, we suggested the basic construction of the compact powerful LED luminaire with the passive air cooling system [34]. Its construction scheme is shown in Fig. 1. The luminaire consists of a base, LED light source, LED driving electronic system as well as the cooling system. The LED source 3 is protected by the light scattering lampshade 4 that can be made as a lens to provide the necessary distribution of the light flux. The electronic driving system 1 for this LED is placed within the zone where it does not prevent propagation of light flow.

The cooling system is assigned to provide operating thermal conditions inherent to powerful LED sources during luminaire operation. The authors of this paper developed a new compact construction for the cooling system of luminaire. In this cooling system, they use highly effective double-phase heat-transmitting facilities - heat pipes, and radiator webbing as an evolved heatexchanged surface. The heat pipes 7 are mounted on the
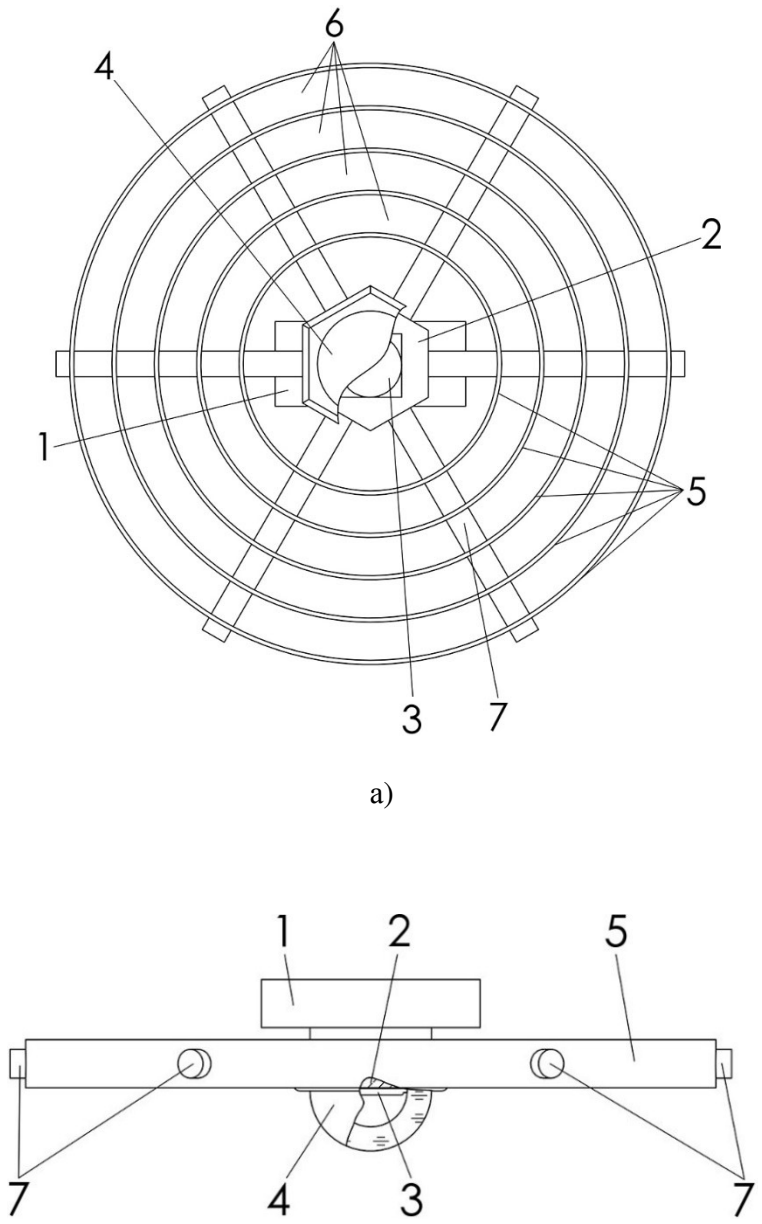

b)

Fig. 1. Bottom (a) and frontal (b) views of the LED luminaire: 1 - LED source driving system, 2 - base, 3 - LED source, 4 - light scatterer, 5 - rings, 6 - air channel, 7 - heat pipes. 
base 2 to provide thermal contact. At the same time, to ensure luminaire compactness the heat pipes in the cooling system are oriented in the radial manner, while the radiator webbing is made in the form of rings 5 and placed concentrically around the LED source 3 [34].

When using horizontal placing of the luminaire, the above approach to design and placement of cooling webbing seems to be the most optimal due to active air motion through the channels between the rings of cooling system. As it follows from the results obtained in [35-37], this placing of cooling webbing enables to use for heat exchange with ambient air all their area with the highest efficiency.

Being based on this basic construction version, one can develop a typical number of LED luminaires that are distinguished between each other by the amount of heat pipes and cooling rings as well as construction parameters of the latter.

The operation principle of the offered cooling system has been described in [33, 36]. Stating briefly, it is as follows. After switching on the luminaire and energizing the LED source 3 (see Fig. 1), the heat flux from this source is transferred to the heat pipes 7 through the heat-conducting base 2. Due to the high heat conductivity of the heat pipes operating in accord with the closed evaporation-condensation cycle, there provided is an efficient heat sink from the LED source 3 and transfer to the cooling rings 5 . Heat sink from the ring surface takes place due to free convection of ambient air. Motion of the latter occurs inside the air channels 6 between the rings of cooling system.

Beforehand, using the method of computer modelling, we investigated the construction of a similar LED luminaire where used were 8 copper-water heat pipes of the diameter $6 \mathrm{~mm}$ with the powder porous capillary structure and 20 cooling rings with the following chosen but non-optimized parameters: the ring height $-50 \mathrm{~mm}$, ring thickness $-2 \mathrm{~mm}$, distance between the rings $-8 \mathrm{~mm}$ [36]. Material of the base and rings - aluminum alloy with the heat conductivity $\lambda=237 \mathrm{~W} /\left(\mathrm{m} \cdot{ }^{\circ} \mathrm{C}\right)$. It was shown that for the power of LED source $500 \mathrm{~W}$ this cooling system provides the temperature of LED semiconductor crystal at the level $139.5{ }^{\circ} \mathrm{C}$, which does not exceed the permissible value of the crystal operation temperature $140{ }^{\circ} \mathrm{C}$. The total thermal resistance of cooling system reaches $0.131^{\circ} \mathrm{C} / \mathrm{W}$.

To reduce the mass and thermal resistance of cooling system, to improve uniformity of heat fluxes by the cooling rings, the amount of the latter and their construction parameters can be optimized. Such optimization performed for definite cooling ring parameters and their amount can enable obtaining the most optimal luminaire construction from the viewpoint of lowering the LED source temperature and luminaire mass.

Defined in this work has been a typical number of constructive versions for LED cooling systems of luminaires, performed also the computer modelling of their thermal and mass characteristics as well as optimization of cooling system for the set diameter of luminaire and power of LED light source.

\section{Computer modelling of thermal parameters for the typical number of construction versions for the cooling system}

To choose an optimal design for the luminaire cooling system, we created a number of models with different construction parameters (Table 1) and performed their computer modelling.

When modelling, we took into account the following requirements that are laid claim to the systems providing heat operation modes for the LED sources:

- construction should ensure the least thermal resistance within a wide range of heat powers;

- cooling system should provide such temperature range of LED operation when the temperature of $p-n$ junctions in semiconductor crystals does not exceed $140{ }^{\circ} \mathrm{C}[6,7]$;

- amount of the material used for creation of the cooling system should be optimized.

For type versions of the cooling system construction that is analyzed, we created a number of models with different parameters of the cooling system. With this aim, we varied the distances between the rings of cooling system, thickness of the cooling rings and heat load. We kept unchanged the ring height $(50 \mathrm{~mm})$, diameter $(6 \mathrm{~mm})$ and amount (8) of heat pipes, shape and sizes of the base (regular octagon prism with the side $31 \mathrm{~mm}$ and height $8 \mathrm{~mm}$ ), dimensions of LED light source $(38 \times 38 \times 1.4 \mathrm{~mm})$, diameter of the largest ring in the cooling system $(516 \mathrm{~mm})$.

Studying the thermal characteristics of these models was carried out using the analytic module FlowSimulation SolidWorks from the computer program SolidWorks.

When creating these computer models, we took into account the following boundary conditions:

- heat pipes are made of copper, heat carrier is distilled water, effective heat conductivity of heat pipes does not depend on temperature and reaches $\lambda_{e f}=10000 \mathrm{~W} /\left(\mathrm{m} \cdot{ }^{\circ} \mathrm{C}\right)$;

- $\quad$ all the other construction elements (except heat pipes) are made of the aluminum alloy, the heat conductivity coefficient of which does not depend on temperature, too, and is equal to $\lambda=$ $237 \mathrm{~W} /\left(\mathrm{m} \cdot{ }^{\circ} \mathrm{C}\right)$;

- $\quad$ thermal emission can be neglected;

- $\quad$ ambient medium is air;

- temperature of the ambient medium is equal to $20{ }^{\circ} \mathrm{C}$;

- $\quad$ atmospheric pressure - $101.325 \mathrm{kPa}$;

- $\quad$ speed of air movement far from luminaire is close to zero;

- heat source is uniformly distributed along the external surface of the model adopted for the LED light source.

The obtained results of our modelling enable to determine the temperature in some characteristic points of the cooling system and to define its suitability for cooling the powerful LED sources. 
Table 1. Typical number of constructive versions for the cooling system of luminaire.

\begin{tabular}{|c|c|c|c|c|c|}
\hline $\begin{array}{c}\text { Version } \\
\text { number }\end{array}$ & $\begin{array}{c}\text { Amount of } \\
\text { rings }\end{array}$ & $\begin{array}{c}\text { Distance } \\
\text { between rings, } \\
\mathrm{mm}\end{array}$ & $\begin{array}{c}\text { Ring thickness, } \\
\mathrm{mm}\end{array}$ & $\begin{array}{c}\text { Total ring surface area for heat } \\
\text { exchange (without heat pipes } \\
\text { and base), } \mathrm{m}^{2}\end{array}$ & $\begin{array}{c}\text { Total area of heat- } \\
\text { exchanging surface, } \\
\mathrm{m}^{2}\end{array}$ \\
\hline 1 & 40 & 3 & 2 & 4.12 & 4.19 \\
\hline 2 & 33 & 4 & 2 & 3.44 & 3.52 \\
\hline 3 & 29 & 5 & 2 & 2.95 & 3.03 \\
\hline 4 & 25 & 6 & 2 & 2.55 & 2.63 \\
\hline 5 & 20 & 8 & 2 & 2.03 & 1.78 \\
\hline 6 & 16 & 10 & 2 & 1.69 & 1.52 \\
\hline 7 & 14 & 13 & 2 & 1.44 & 1.13 \\
\hline 8 & 10 & 18 & 2 & 1.05 & \\
\hline
\end{tabular}

Table 2. Thermal and mass characteristics of construction versions for the cooling system of LED luminaire, when the ring thickness is $2 \mathrm{~mm}$.

\begin{tabular}{|c|c|c|c|c|}
\hline $\begin{array}{c}\text { Number } \\
\text { of version }\end{array}$ & $\begin{array}{c}\text { Maximum temperature } \\
\text { of the LED case, }{ }^{\circ} \mathrm{C}\end{array}$ & $\begin{array}{c}\text { Mass of the cooling } \\
\text { system, } \mathrm{g}\end{array}$ & $\begin{array}{c}\text { Temperature change } \\
\text { relatively to the version } 4, \%\end{array}$ & $\begin{array}{c}\text { Mass change relatively to the } \\
\text { version } 4, \%\end{array}$ \\
\hline 1 & 97.2 & 10682 & 16.1 & 61.5 \\
\hline 2 & 88.8 & 8729 & 6.1 & 32.0 \\
\hline 3 & 84.5 & 7769 & 1.0 & 0.5 \\
\hline 4 & 83.7 & 6613 & 0.0 & -20.5 \\
\hline 5 & 85.5 & 5256 & 2.2 & -33.5 \\
\hline 6 & 89.3 & 4395 & 6.7 & -43.5 \\
\hline 7 & 95.7 & 3739 & 14.3 & -59.0 \\
\hline 8 & 105.1 & 2713 & 25.6 & \\
\hline
\end{tabular}

\section{Results of the computer modelling and their analysis}

Shown in Fig. 2 are the results of our computer modelling of the temperature distribution along the cooling system for the case when the distance between cooling rings changes from 3 up to $18 \mathrm{~mm}$ and the thickness of each ring is $2 \mathrm{~mm}$. When the outer diameter of luminaire is kept constant, the change of inter-ring distance simultaneously varies the amount of rings and defines the effect on the total area of the heat-conducting radiator surface. Therefore, this increase in the amount of rings should result in changing the temperature of LED source.

In the considered cooling system, the convective heat exchange with air occurs mainly due to free convection of air through the channels between the cooling rings. The area of all the other surfaces taking part in the heat exchange with air reaches 0.025 up to $0.035 \mathrm{~m}^{2}$, which does not exceed $3.1 \%$ of the total area of the heat-exchanging surface inherent to the considered cooling system. Shown in Fig. 3 is the dependence of the area of the total cooling system surface that takes part in the heat exchange on the distance between cooling rings. This dependence has a monotonous falling character with the inflection point corresponding to the distance $8 \mathrm{~mm}$ between cooling rings.
Shown in Fig. 4 is the change of the maximum temperature inherent to the case of LED source with changing the distance between rings. As can be seen in this figure, the dependence of the LED source case on the distance between cooling rings has its pronounced extremum, which enables to determine the optimum value of this distance. The minimum value of temperature inherent to the LED source case is $83.7^{\circ} \mathrm{C}$ and reached for the distance between cooling rings $6 \mathrm{~mm}$ (construction version 4). In this case, the area of the cooling system heat-exchanging surface is equal to $2.63 \mathrm{~m}^{2}$.

When the distance between rings becomes shorter than $6 \mathrm{~mm}$, the LED source case temperature begins to increase, despite the growth of total area of cooling webbing. It is explained by the fact that, for too small distance between the rings, the hydraulic resistance for air movement in the channels between rings grows, and the velocity of air motion through the cooling channels is lowered, which results in reducing the coefficient of heat exchange between the ring surface and ambient air.

In the case when cooling rings are placed at the distance $8 \mathrm{~mm}$ one to another (construction version 5), the amount of rings is decreased by 5 pieces. At the cost of it, the cooling system heat-exchanging surface area decreases down to $2.11 \mathrm{~m}^{2}$, which is $24 \%$ lower than that for placing the cooling rings with the step $6 \mathrm{~mm}$ (see Table 1). 


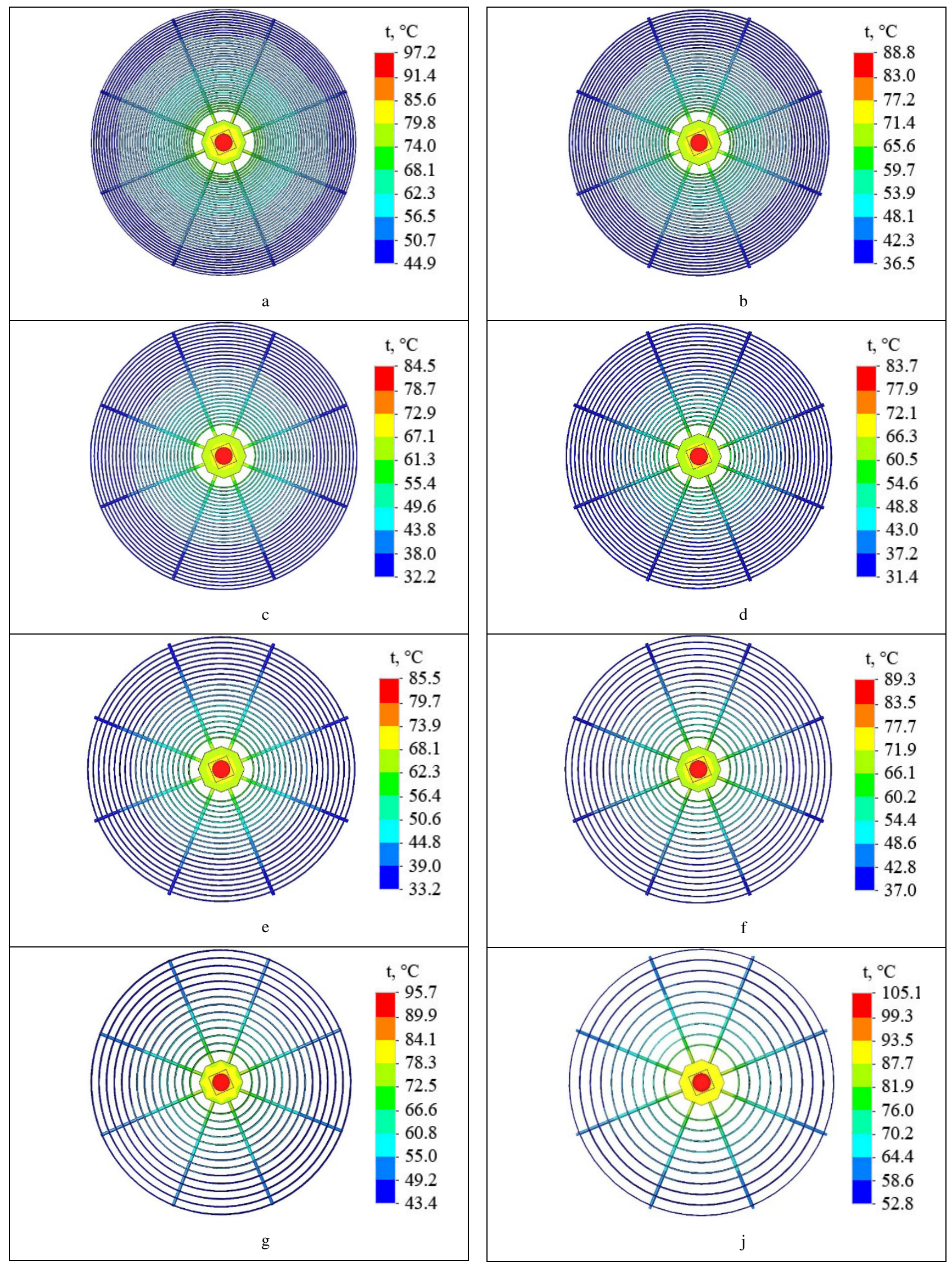

Fig. 2. Images of temperature distributions for the LED source heat power $500 \mathrm{~W}$ and various distances between the rings, mm: (a) -3 ; (b) -4 ; (c) -5 ; (d) -6 ; (e) -8 ; (f) $-10 ;($ g) -13 ; (j) -18 .

Pekur D.V., Nikolaenko Yu.E., Sorokin V.M. Optimization of the cooling system design for a compact high-power ... 


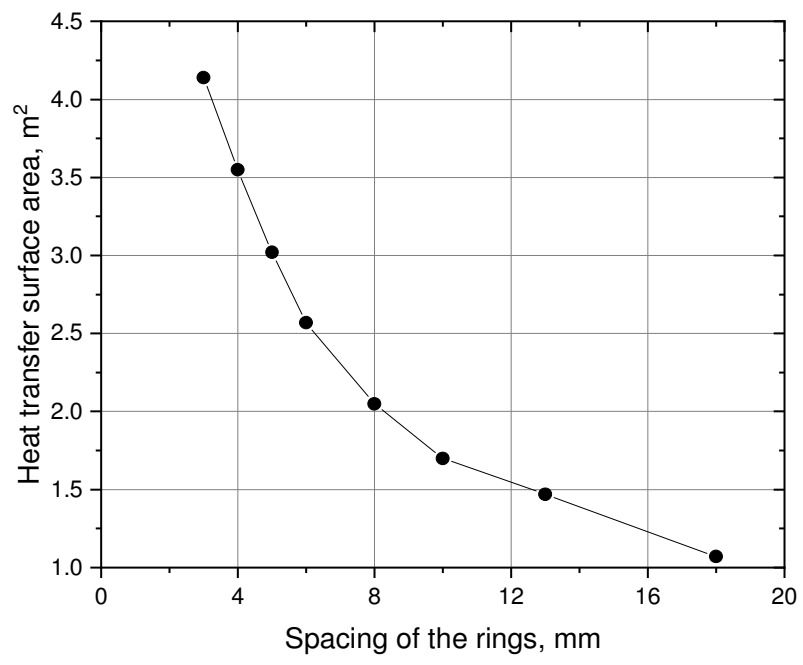

Fig. 3. Dependence of the total area of cooling system heatexchanging surface on the distance between cooling rings.

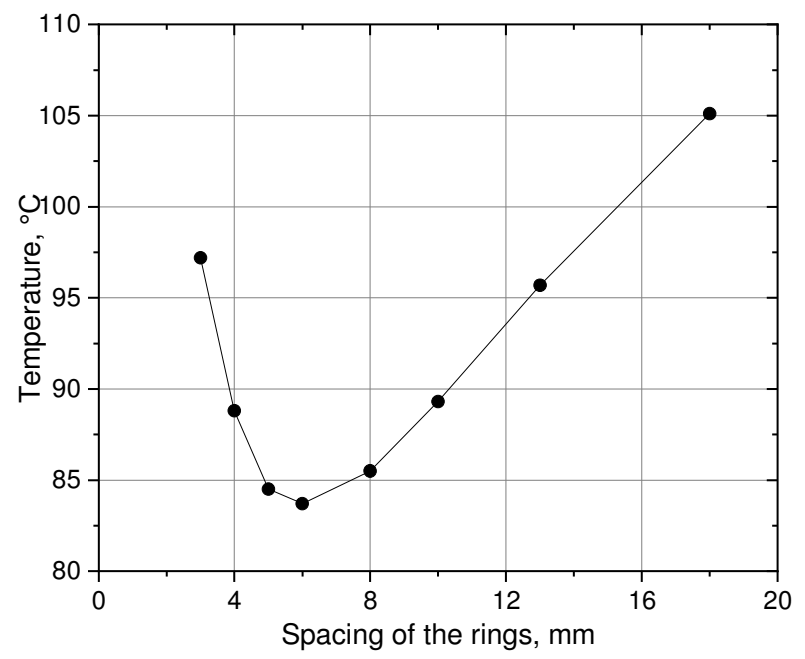

Fig. 4. Dependence of the LED source case maximum temperature on the distance between cooling rings for the heat power $500 \mathrm{~W}$.

However, this decrease in the amount and surface area of the rings leads to lowering their mass by $1357 \mathrm{~g}$ as well as increasing the temperature only by $1.8^{\circ} \mathrm{C}$ (Table 2 ).

Although further increasing the distance between rings and decreasing their amount lowers the cooling system mass, however, it leads to a sharp increase in the temperature of LED light source. It can be explained by reduction of the cooling system total area. For example, in the case when the distance between cooling rings reaches 10,13 and $18 \mathrm{~mm}$ (construction versions 6,7 and 8 ) the cooling system mass drops by $33.5 \%, 43.5 \%$ and $59 \%$, respectively, as compared with the version 4 , however, the temperature of LED light source increases by $6.7 \%, 14.3 \%$ and $25.6 \%$ (see Table 2 ).

Thereof, the most reasonable, from the viewpoint of practical applications, is the constructive version 5 with the distance between the rings $8 \mathrm{~mm}$, which provides the

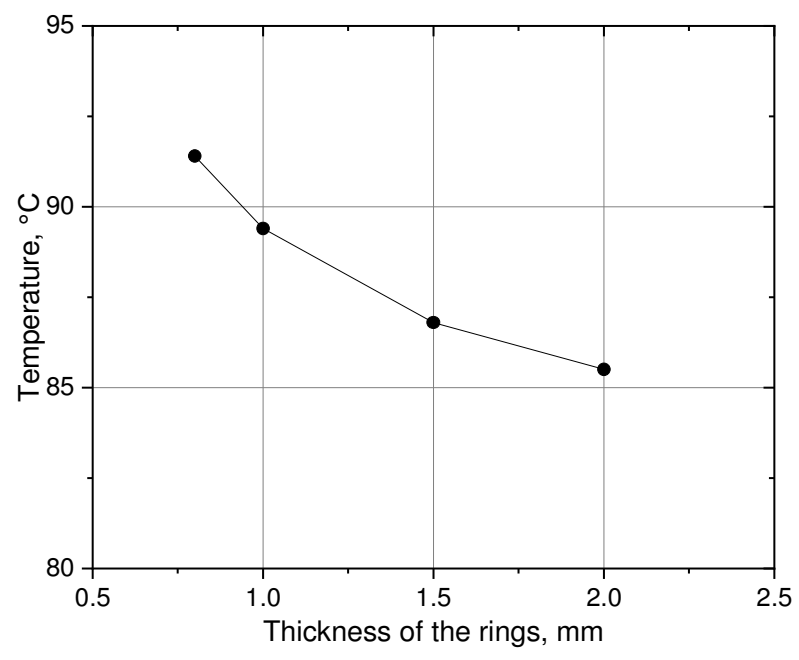

Fig. 5. Dependence of the maximum temperature value inherent to the LED source case on the ring thickness.

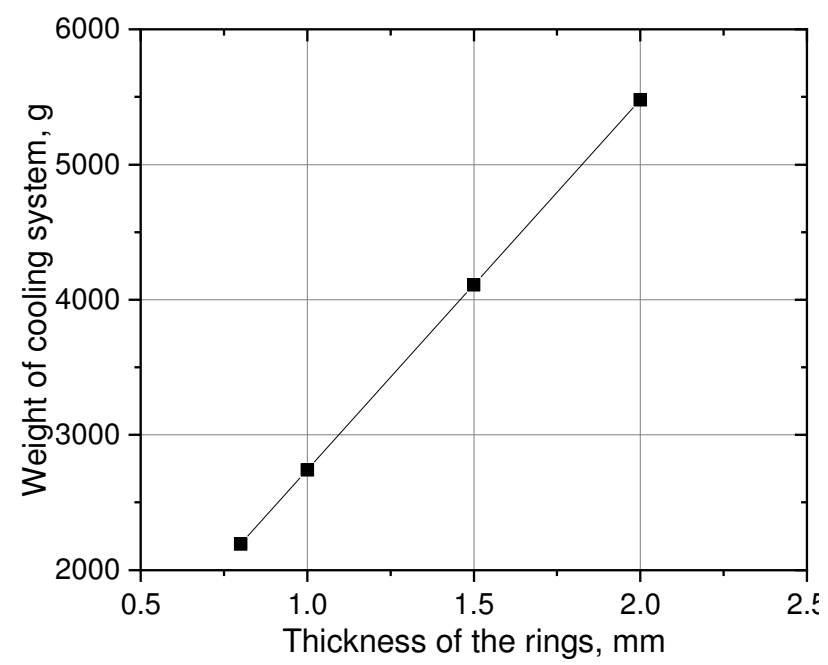

Fig. 6. Dependence of the cooling system mass on the ring thickness.

LED source case temperature $85.5^{\circ} \mathrm{C}$ and has the worse mass characteristics than those of the construction version 4.

Let us analyze the influence of ring thickness on the luminaire thermal and mass characteristics. The dependences of maximum temperature inherent to the LED source case and cooling system mass on the ring thickness for their diameter defined at their step $8 \mathrm{~mm}$ and thickness $2 \mathrm{~mm}$ are shown in Figs 5 and 6, respectively.

It is worth to note that, on the one hand, when the ring thickness is decreased the cooling system mass is decreased to some extent, too, and the width of air channels increases, which enhances air circulation in them. On the other hand, when the ring thickness is decreased, its thermal resistance concerning propagation of the heat flow from the heat pipe along the ring is increased, which is related with the negative effect on the 


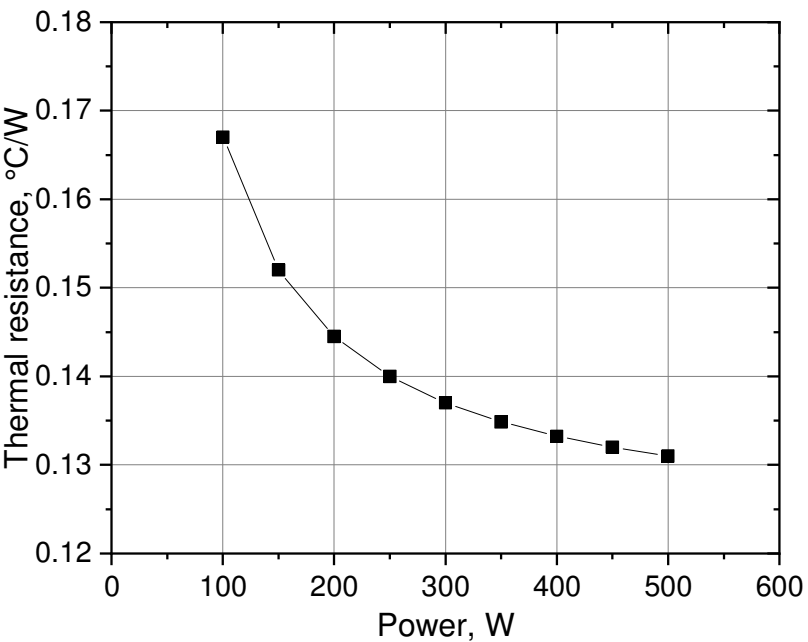

Fig. 7. Thermal resistance of the cooling system for various powers of the LED source.

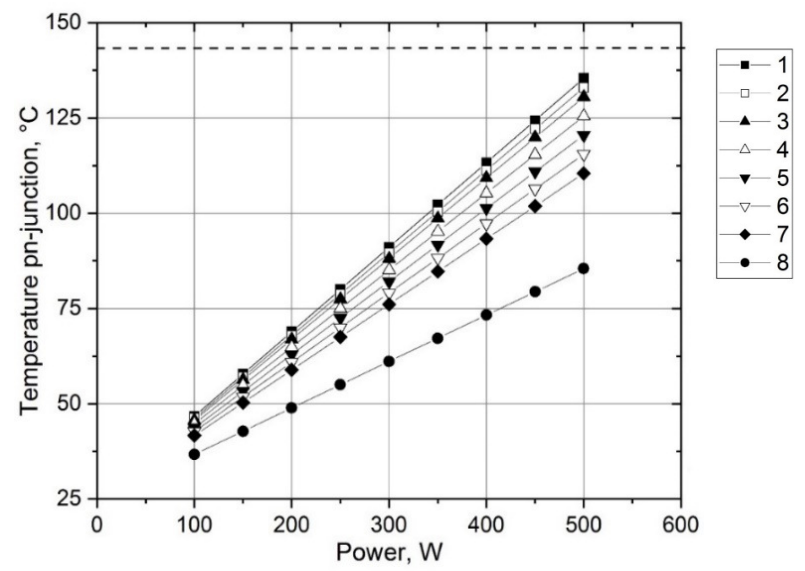

Fig. 8. Dependence of the temperature inherent to $p$ - $n$ junction on power for various values of the coefficients of electrical power transformation into the thermal one: $1-100 \%, 2-95 \%$, $3-90 \%, 4-80 \%, 5-70 \%, 6-60 \%, 7-50 \%$ as well as the temperature of the LED case on the power -8 .

temperature of the LED source case. As seen from Fig. 5, the decease in the ring thickness from 2 down to $0.8 \mathrm{~mm}$ leads to increasing the temperature of LED source case from 85.5 up to $91.4{ }^{\circ} \mathrm{C}$.

The LED source temperature change by $5.9{ }^{\circ} \mathrm{C}$ is sufficiently low as compared relatively to the overall temperature drop in the cooling system between the LED source case and air $\left(65.5-71.4{ }^{\circ} \mathrm{C}\right)$, but enables to essentially (by $48.6 \%$ or $2700 \mathrm{~g}$ ) lower the cooling system mass (Fig. 6).

The important parameter of the cooling system is its thermal resistance. Since the developed cooling system with heat pipes can be used in LED luminaires of various powers inherent to LED sources, then for practical application it is desirable to know how the thermal resistance will change after changing the LED source power. To answer this question, we performed computer modelling

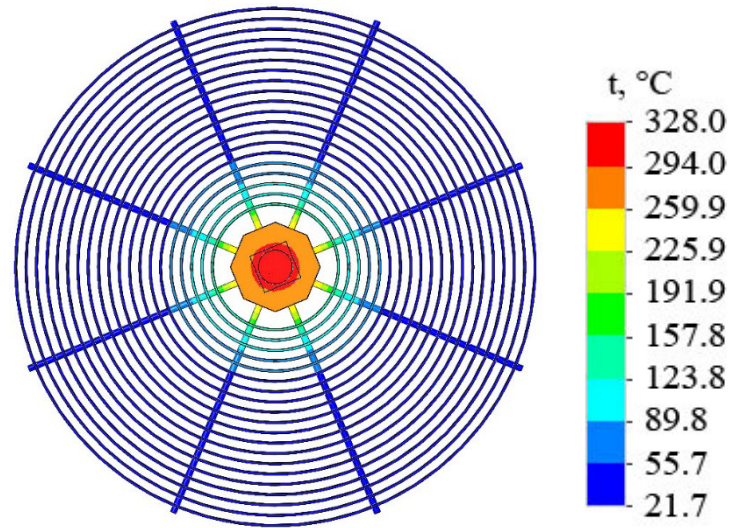

Fig. 9. Distribution of temperature over the LED luminaire cooling system when using the copper bars instead of heat pipes.

of the cooling system thermal parameters for the construction version 5 when changing the LED source power from 100 up to $500 \mathrm{~W}$ with the step of $50 \mathrm{~W}$.

The cooling system thermal resistance was determined using the expression (1) described in [27]:

$R_{\text {thermal }}=\frac{t_{\max }-t_{a}}{p}$

where $t_{\max }$ is the maximum temperature of the cooling system in ${ }^{\circ} \mathrm{C}, t_{a}$ - temperature of the ambient medium in ${ }^{\circ} \mathrm{C}, p$ - thermal power in watts that is scattered.

Adduced in Table 3 are the calculated using the formula (1) values of the thermal resistance inherent to the LED luminaire cooling system with 20 rings of the thickness $2 \mathrm{~mm}$ and the distance between them $8 \mathrm{~mm}$, when the temperature of ambient air is close to $20{ }^{\circ} \mathrm{C}$. Fig. 7 shows the dynamics of changing the thermal resistance of the cooling system of this configuration with the LED source thermal power. As seen from this figure, this dependence has a monotonically-decaying character. When the LED source thermal power is increased, the thermal resistance of cooling system is decreased. The reason for this behavior is that the increase in the thermal power raises the temperature of cooling rings and enhances the speed of air motion in cooling channels. The growth of air flux increases the value of coefficient for convective heat exchange between ring surface and air, which results in lowering the thermal resistance of cooling system.

The performed calculations show that within the range of powers for 100 up to $500 \mathrm{~W}$ the thermal resistance of the cooling system decreases from 0.167 down to $0.131{ }^{\circ} \mathrm{C} / \mathrm{W}$. This factor of the thermal resistance enables to use in the LED luminaire design powerful LEDs and COB-modules with the thermal package $500 \mathrm{~W}$ and to keep the LED case temperature not higher than $85.5^{\circ} \mathrm{C}$. When doing so, the temperature 
Table 3. Thermal resistance of the LED cooling system for the construction version 5 under various values of the thermal power.

\begin{tabular}{|l|c|c|c|c|c|c|c|c|c|}
\hline Power, W & 100 & 150 & 200 & 250 & 300 & 350 & 400 & 450 & 500 \\
\hline$T_{\max },{ }^{\circ} \mathrm{C}$ & 36.7 & 42.8 & 48.9 & 55.0 & 61.1 & 67.2 & 73.3 & 79.4 & 85.5 \\
\hline Thermal resistance, ${ }^{\circ} \mathrm{C} / \mathrm{W}$ & 0.167 & 0.152 & 0.145 & 0.140 & 0.137 & 0.135 & 0.133 & 0.132 & 0.131 \\
\hline
\end{tabular}

of LED source semiconductor crystals will depend on the amount of supplied electrical energy transformed into the thermal one. As usual, the fraction of supplied electrical energy transformed into the thermal one is higher than $50 \%$.

To determine the temperature of LED semiconductor crystal $T_{\text {junction, }}$ one can use the expression (2) for the temperature of crystal $p$ - $n$ junction on the power and temperature of LED case [27]:

$$
T_{\text {junction }}=T_{\text {case LED }}+\eta \cdot P_{\text {electric }} \cdot R_{\text {thermal junction-case LED }} \text {, }
$$

where $T_{\text {case LED }}$ is the temperature of LED case, ${ }^{\circ} \mathrm{C} ; \eta-$ coefficient of electrical energy transformation into the thermal one; $P_{\text {electric }}$ - total electric power, W; $R_{\text {thermal junction-case } L E D}$ - thermal resistance of the spacing between the case and $p-n$ junction of $\mathrm{LED},{ }^{\circ} \mathrm{C} / \mathrm{W}$.

Shown in Fig. 8 is the calculation dependence of the LED crystal temperature on the power for various values of the coefficient of electrical energy transformation into the light one within the range $0 \%$ up to $50 \%$.

It is seen from Fig. 8 that even under conditions when all the electric energy is transformed into the thermal one, the temperature of $p-n$ junction cannot approach to the permissible operation critical value for this type of LEDs $140{ }^{\circ} \mathrm{C}$ (in Fig. 8, it is shown with the dashed line).

Besides, to demonstrate the efficiency of the developed compact cooling system based on heat pipes, in this work we performed the computer modelling of an analogous cooling system where instead of heat pipes the copper bars with the same geometrical sizes were used (diameter $6 \mathrm{~mm}$, length $250 \mathrm{~mm}$ ). The copper thermal conductivity was taken to be $400 \mathrm{~W} /\left(\mathrm{m} \cdot{ }^{\circ} \mathrm{C}\right)$. In this case, we used the cooling rings of the thickness $2 \mathrm{~mm}$ and height $50 \mathrm{~mm}$ at the distance $8 \mathrm{~mm}$ (analog of the construction version 5). As shown in Fig. 9, the maximum temperature of the LED source case with the same power $500 \mathrm{~W}$, when using the copper bars instead of heat pipes, could be close to $328^{\circ} \mathrm{C}$.

As shown by using additional calculations, to provide the parameters of heat sink similar to those typical for the cooling system with heat pipes of the 6-mm diameter, the homogeneous copper bars of the length $250 \mathrm{~mm}$ should have the diameter $30 \mathrm{~mm}$, while those from aluminum $-39 \mathrm{~mm}$. In this case, the mass of these bars should be at least 65 and 34 times higher, respectively, than the mass of heat pipes considered in the developed cooling system (version 5).

\section{Recommendations for practical application of the developed luminaire}

When designing the LED luminaire with a set power for specific practical applications, first of all, it is necessary to define what its characteristics are more critical under these conditions of operation: temperature of the LED source or the mass of luminaire. In accord with them, it should be chosen the respective construction version of luminaire. In the first case, preference should be given to the construction versions 3 to 5 the most close to the optimum one from the viewpoint of lowering the temperature of light source. In the second one - to the versions 6 to 8 providing the less ring thickness, which corresponds to a less luminaire mass. However, in this case, it is necessary to provide the LED source temperature that does not exceed the maximum permissible value.

Due to the low height, the developed LED luminaire can be applied both for lighting the living spaces with low ceilings and for internal lighting the cabins, bodies, staterooms and other premises of many transportations. Specificity of exploitation conditions inherent to transport vehicles places a demand to the luminaire producer performing the thermal calculations for its cooling system to take into account the possible effects of vibrations, accelerations and shocks on characteristics of heat pipes [39-46] and, accordingly, of the whole luminaire.

If it is necessary, in perspective modifications of LED luminaires for special purposes, one can use LED sources with the power higher than $500 \mathrm{~W}$. In this case, it is purposeful to choose larger amount of heat pipes and rings. Besides, to disperse the high thermal flux over the whole surface of carrying base, it is reasonable to use heat-distributing spacers between $\mathrm{COB}$ matrix and carrying base in the form of thin vapor chambers [47-49] that also operate using the closed evaporationcondensation cycle for heat transmitting.

\section{Conclusions}

1. It has been performed optimization of construction of the passive air cooling system for a compact powerful LED luminaire, which is based on heat pipes and cooling rings, by using the updated programs for computer modelling and analysis. It enables to study the thermal operation regimes and mass characteristics of the designed cooling system before producing it.

2. Comparison of the maximum temperature observed on the body of LED source for various distances between the rings of cooling system has shown 
that lowering or increasing the distance as compared with its optimal value $6 \mathrm{~mm}$ leads to enhancing the temperature of the LED source body. With account of the said above, the most reasonable for practical applications is the distance between cooling rings equal to $8 \mathrm{~mm}$, which in comparison $6 \mathrm{~mm}$ increases the temperature by only $1.8{ }^{\circ} \mathrm{C}$ (i.e., by $2.2 \%$ ) for lowering the used material mass by $1357 \mathrm{~g}$ or by $20.5 \%$.

3. Reducing the cooling rings thickness from 2 down to $0.8 \mathrm{~mm}$ leads to increasing the LED source body temperature for its power $500 \mathrm{~W}$ by $5.9{ }^{\circ} \mathrm{C}(6.9 \%)$, however, there reached is an essential gain in the mass of cooling system, namely: the amount of used material and mass for producing it is decreased by $2.3-1.8$ times.

4. If one uses in the construction of cooling system for the LED luminaire instead of the heat pipes the copper bars with the same dimensions, the temperature of the LED source body will increase up to $328^{\circ} \mathrm{C}$, which is unallowable from the viewpoint of luminaire operation reliability. To reach the thermal regimes that are provided by heat pipes, it would be necessary to 5-fold increase the diameter of copper bars. Then the mass of these bars will be 65 times increased.

5. It has been offered recommendations concerning practical applications of the developed LED luminaire.

\section{References}

1. LEDs and their Application in Lighting. Under general edition by Academician Yu.B. Aisenberg. Moscow, "Znak", 2012 (in Russian).

2. Cree Inc. URL: https: //www.cree.com/ledcomponents/media/documents/ LM80_Results.pdf (reference date: 15.12.19).

3. Illuminating Engineering Society, LM-80-08, Approved Method: Measuring Lumen Maintenance of LED Light Sources, 2008.

4. Illuminating Engineering Society, LM-79-08, Electrical and Photometric Measurements of SolidState Lighting Products, 2008.

5. Illuminating Engineering Society, TM-21-11, Projecting Long Term Lumen Maintenance of LED Light Sources, 2012.

6. CITIZEN ELECTRONICS CO., LTD. http://ce.citizen.co.jp/lighting_led/dl_data/datasheet /en/COB_4/CLU056-1825C1_P3099_0415.pdf (reference date: 10.12.19).

7. Ursaki A. Development of Chip-on-Board LED modules by the example of matrix evolution from Citizen Electronics. Sovremennaja svetoteknika. 2018. No 2. P. 20-22 (in Russian).

8. Kozak D.V., Nikolaenko Yu.E. The working characteristics of two-phase heat transfer devices for LED modules. 2016 IEEE International Conference on Electronics and Information Technology (EIT'16), Ukraine, Odessa, May 23-27, 2016. IEEE. P. 1-4.

https://doi.org/10.1109/ICEAIT.2016.7500980.

9. Hai Wang, Jian Qu, Youquan Peng, Qin Sun. Heat transfer performance of a novel tubular oscillating heat pipe with sintered copper particles inside flatplate evaporator and high-power LED heat sink application. Energy Conversion and Management. 2019. 189. P. 215-222.

https://doi.org/10.1016/j.enconman.2019.03.093.

10. Kiseev V., Aminev D., Sazhin O. Two-phase nanofluid-based thermal management systems for LED cooling. IOP Conf. Ser.: Mater. Sci. Eng. 2017. 192, No. 1. 012020. P. 1-7.

https://doi.org/10.1088/1757-899X/192/1/012020.

11. Tang, Y., Chen, Q., Guan, W., Li Z., Yu B., Yu. W. Thermal analysis of an LED module with a novelly assembled heat pipe heat sink. J. Cent. South Univ. 2017. 24, Issue 4. P. 921-928. https://doi.org/10.1007/s11771-017-3494-9.

12. Li J., Tian W., Lv L. A thermosyphon heat pipe cooler for high power LEDs cooling. Heat Mass Transfer. 2015. 52, No 8. P. 1541-1548. http://dx.doi.org/10.1007/s00231-015-1679-z.

13. Wu Y., Tang Y., Li Z., Ding X., Yuan W., Zhao X., $\mathrm{Yu}$ B. Experimental investigation of a PCM-HP heat sink on its thermal performance and antithermal-shock capacity for high-power LEDs. Appl. Therm. Eng. 2016. 108. P. 192-203. https:// doi.org/10.1016/j.applthermaleng.2016.07.127.

14. Nikolaenko Yu. E., Alekseik E.S., Kozak D.V., Nikolaienko T.Yu.. Research on two-phase heat removal devices for power electronics. Thermal Science and Engineering Progress. 2018. 8. P. 418-425. https://doi.org/10.1016/j.tsep.2018.09.012.

15. Huaiyu Ye, Bo Li, Hongyu Tang, Jia Zhao, Cadmus Yuan, Guoqi Zhang. Design of vertical fin arrays with heat pipes used for high-power light-emitting diodes. Microelectronics Reliability. 2014. 4, Issue 11. P. 2448-2455. https://doi.org/10.1016/j.microrel.2014.05.004.

16. Vasil'ev L.L. Jr, Grakovich L.P., Dragun L.A., Zhuravlev A.S., Olekhnovich V.A., Rabetskii M.I. System for cooling of electronic components. Journal of Engineering Physics and Thermophysics. 2017. 90, No. 1. P. 95-101. http://dx.doi.org/10.1007/s10891-017-1543-8.

17. Shu S., Hou G., Wang L., Tian S., Vassiliev L.L., Tong, C. Heat dissipation in high-power semiconductor lasers with heat pipe cooling system. J. Mech. Sci. Technol. 2017. 31, No. 6. P. 2607-2612. https://doi.org/10.1007/s12206-017-0502-9.

18. Nikolaenko Yu.E. Schematics of the architecture of heat rejection from functional modules of a computer with the help of two-phase heat-transfer devices. Upravliayushchie Sistemy $i$ Mashiny. 2005. No. 2. P. 29-36.

http://ela.kpi.ua/handle/123456789/16362; http://www.scopus.com/inward/record.url?eid=2s2.0-33644653599\&partnerID=MN8TOARS.

19. Gvozdev S.M., Mitrofanov A.V., Safonov S.A., Kholodilov V.I. On the usage of heat pipes in designing the powerful LED luminaires. Svetotekhnika. 2012. No 2. P. 19-21 (in Russian). 
20. Mehmet Kaya. Experimental study on active cooling systems used for thermal management of high-power multichip light-emitting diodes. Scientific World Journal. 2014. 563805. P. 1-7. http://dx.doi.org/10.1155/2014/563805.

21. Ding X. R., Li Y. J., Li Z. T., Tang Y., Yu B. H., Yuan D. The Application of Heat Pipe Heat Sink for High Power LED Lamps. Applied Mechanics and Materials. 2014. 602-605. P. 2713-2716. https://doi.org/10.4028/www.scientific.net/AMM.6 02-605.2713.

22. Melnyk R.S., Nikolaenko Yu.E., Alekseik Ye.S., Kravets V.Yu. Heat transfer limitations of heat pipes for a cooling systems of electronic components. The 2017 IEEE First Ukraine Conference on Electrical and Computer Engineering (UKRCON), Kyiv, Ukraine, May 29 June 2, 2017. P. 692-695. https://doi.org/10.1109/UKRCON.2017.8100316.

23. Zhibin W., Yuebin Z., Zhong-dong W., Shasha X., Yang H. Study on Heat Pipe Sink for cooling High Power LED. Proc. SPIE. 2012. 8419. P. 84193C. https://doi.org/10.1117/12.976018.

24. Xiang-you Lu, Tse-Chao Hua, Yan-ping Wang, Thermal analysis of high power LED package with heat pipe heat sink. Microelectronics Journal. 2011. 42, Issue 11. P. 1257-1262.

https://doi.org/10.1016/j.mejo.2011.08.009

25. Nikolaenko Yu.E., Pekur D.V., Sorokin V.M. Light characteristics of high-power LED luminaire with a cooling system based on heat pipe. Semiconductor Physics, Quantum Electronics \& Optoelectronics. 2019. 22, No 3. P. 366-371.

https://doi.org/10.15407/spqeo22.03.366

26. Nikolaenko Yu.E., Kravets V.Yu., Naumova A.N. Baranyuk A.V. Development of the ways to increase the lighting energy efficiency of living space. International Journal of Energy for a Clean Environment. 2017. 18, Issue 3. P. 275-285. https:// doi.org/10.1615/InterJEnerCleanEnv.2018021641.

27. Nikolaenko T.Yu., Nikolaenko Yu.E. New circuit solutions for the thermal design of chandeliers with Light Emitting Diodes. Light \& Engineering. 2015. 23, No 3. P. 85-88.

http://www.scopus.com/inward/record.url?eid=2s2.0-84966507707\&partnerID=MN8TOARS

28. Idrus F., Mohamad N., Zailani R., Wisnoe W., Abdullah M.Z. Thermal performance of a cylindrical heat pipe for different heat inputs and inclination angles. Applied Mechanics and Materials. 2014. 661. P. 148-153.

https://doi.org/10.4028/www.scientific.net/amm.66 1.148.

29. Drofenik U., Stupar A., Kolar J.W. Analysis of theoretical limits of forced-air cooling using advanced composite materials with high thermal conductivities. IEEE Transactions on Components, Packaging, and Manufacturing Technology. 2011. 1, № 4. P. 528-535.

https://doi.org/10.1109/TCPMT.2010.2100730.
30. Kurowski Paul M. Thermal Analysis with SOLIDWORKS Simulation 2015.

31. Wang H., Wang P., Liu J., Xiong D. Establishing thermal model for the design of the high-power led headlight cooling device. 15th China International Forum on Solid State Lighting: International Forum on Wide Bandgap Semiconductors China (SSLChina: IFWS). 2018. P. 150-153. https://doi.org/10.1109/IFWS.2018.8587360.

32. Hrabovsky P., Z Kolkova., Mokry M., Nemec P. Basic CFD model of heat pipe. MATEC Web of Conferences. 2018. 168. P. 02014. https://doi.org/10.1051/matecconf/201816802014.

33. Pekur D.V., Nikolaenko Yu.E., Sorokin V.M. New led lamp design with heat pipes. Tekhnologiya $i$ Konstruirovanie v Elektronnoi Apparature. 2019. No. 5-6. P. 34-42. http://dx.doi.org/10.15222/TKEA2019.5-6.34.

34. Sorokin V.M., Pekur D.V. Nikolaenko Yu.Ye. Patent of Ukraine for the useful model. Patent application u201910273 from 09.10.2019.

35. Cucumo M., Ferraro V., Kaliakatsos D., Marinelli V. Theoretical and experimental analysis of the performances of a heat sink with vertical orientation in natural convection. Int. J. Energy Environ. Eng. 2017. 8, Issue 3. P. 247-257. https://doi.org/10.1007/s40095-014-0144-y.

36. Pekur D.V., Sorokin V.M., Nikolaenko Yu.E. Thermal characteristics of a compact LED luminaire with a cooling system based on heat pipes. Therm. Sci. Eng. Progress. 2020. 18.

37. Qie Shen, Daming Sun, Ya Xu,Tao Jin, Xu Zhao. Orientation effects on natural convection heat dissipation of rectangular fin heat sinks mounted on LEDs. International Journal of Heat and Mass Transfer. 2014. 75. P. 462-469. https://doi.org/ 10.1016/j.ijheatmasstransfer.2014.03.085.

38. Cree Inc. https://www.cree.com/led-components/ media/documents/XLampThermalManagement.pdf (reference date: 15.12.19).

39. Alaei Amir, Kafshgari Morteza Hasanzadeh, Rahimi Shahab Kashani. A vertical heat pipe: an experimental and statistical study of the thermal performance in the presence of low-frequency vibrations. Heat Mass Transfer. 2013. 49. P. 285290. https://doi.org/10.1007/s00231-012-1057-z.

40. Prisniakov K., Marchenko O., Melikaev Yu., Kravetz V., Nikolaenko Yu., Prisniakov V. About Complex Influence of Vibrations and Gravitational Fields on Serviceability of Heat Pipes in Composition of the Space-Rocket Systems. 54th International Astronautical Congress of the International Astronautical Federation (IAF), the International Academy of Astronautics and the International Institute of Space Law, International Astronautical Congress (IAF). Bremen, Germany. 2003. 1. P. 1571-1580. http://dx.doi.org/10.2514/6.IAC-03-I.1.10; http://www.scopus.com/inward/record.url?eid=2s2.0-22344442816\&partnerID=MN8TOARS. 
41. Zaghdoudi M.C., Tantolin C., Sarno C. Acceleration and vibration effects on the thermal performance of a two-phase heat spreader with embedded flat mini heat pipes. International Review of Aerospace Engineering (I.RE.AS.E), 2011. 4, No. 2. P. 109-121.

42. Marchenko O., Prisniakov K., Prisniakov V., Kravez V., Nikolaenko Yu. Influence of NonStationary Conditions on Reliability of Space Systems with Heat Pipes under the Effect of Vibrations. 55th International Astronautical Congress of the International Astronautical Federation, the International Academy of Astronautics, and the International Institute of Space Law, International Astronautical Congress $(I A F)$, Vancouver, British Columbia, Canada. 2004. 4. P. 2301-2311. https://doi.org/10.2514/6.IAC-04-I.P.04.

43. Chen R.H., Lin Y.J., Lai C.M. The Influence of Horizontal Longitudinal Vibrations and the Condensation Section Temperature on the Heat Transfer Performance of a Heat Pipe. Heat Transfer Engineering. 2013. 34, Is. 1. P. 45-53. https://doi.org/10.1080/01457632.2013.694776.

44. Zaghdoudi M.C., Tantolin C., Sarno C. Experimental investigation on the use of Flat Mini Heat Pipes for avionics electronic modules cooling. International Review of Mechanical Engineering. 2011. 5, No. 4. P. 770-883.

45. Zaghdoudi M.C., Tantolin C., Sarno C. Effects of acceleration forces on the thermal performances on flat heat pipes with different capillary structures. Proc. 16th Intern. Heat Pipe Conf. (16th IHPC), Lyon, France, May 20-24, 2012. P. 123-128.

46. Hsu C.C., Chen X.F. and Yang, J.M. The Effects of Shock and Vibration on Heat Pipe Performance in Reliability Tests. 10th Intern. Heat Pipe Conf., Taipei, Taiwan, November 6-9, 2011. P. 267-271.

47. Chen Y., Li B., Wang X., Yan Y., Wang Y., Qi F. Investigation of heat transfer and thermal stresses of novel thermal management system integrated with vapour chamber for IGBT power module. Therm. Sci. Eng. Progress. 2019. 10. P. 73-81. https://doi.org/10.1016/j.tsep.2019.01.007.

48. Nikolaenko Yu.E., Rotner S.M. Using laser radiation for the formation of capillary structure in flat ceramic heat pipes. Techn. Phys. Lett. 2012. 38, No 12. P. 1056-1058.

https://doi.org/10.1134/S1063785012120085.

49. Qingjun Cai1, Bing-chung Chen, and Chialun Tsai, Design, development and tests of high-performance silicon vapor chamber. J. Micromech. Microeng. 2012. 22, 035009, P. 1-9.

http://dx.doi.org/10.1088/0960-1317/22/3/035009.

\section{Authors and CV}

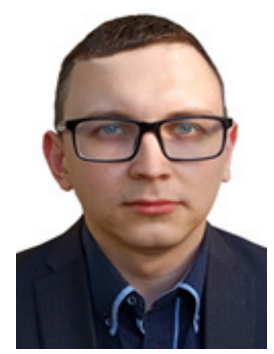

Demid V. Pekur, Ph.D. student at the V. Lashkaryov Institute of Semiconductor Physics, NASU. The area of his scientific interests includes design of perspective cooling systems for super-power LEDs and creation of LED facilities on them.

Scopus Author ID: 57211485091

ORCID: https://orcid.org/0000-00024342-5717

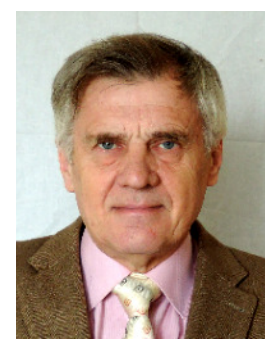

Yurii E. Nikolaenko, Doctor of Engineering, Leading fellow of the heat-and-power engineering department at the National Technical University of Ukraine "Igor Sikorsky Kyiv Polytechnic Institute". Field of scientific interests: heat removal from electronic components by using heat pipes.

Scopus Author ID: 23393308200

ORCID: http://orcid.org/0000-0002-3036-5305

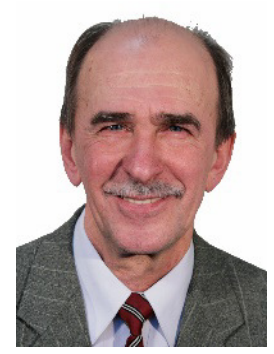

Viktor M. Sorokin, Professor, Doctor of Sciences, Corresponding Member of the National Academy of Sciences of Ukraine, Head of the Department of Optoelectronics at the V. Lashkaryov Institute of Semiconductor Physics, NAS of Ukraine. The author of more than 200 publications. His research interests include problems of liquid crystal materials science, lighting engineering and lighting materials. He organized massive implementation of LED lighting in Ukraine. He is the State Prize winner of Ukraine in the field of science and technology.

Scopus Author ID: 7201463453

ORCID: https://orcid.org/0000-0002-1499-1357 